\title{
PERIBULBAR ANAESTHESIA FOR CATARACT SURGERY: PRILOCAINE VERSUS LIGNOCAINE AND BUPIVACAINE
}

\author{
T. R. M. HENDERSON and W. FRANKS \\ York
}

\begin{abstract}
SUMMARY
Purpose. Prilocaine has recently been introduced for use in ocular local anaesthesia. A prospective randomised double-masked study was undertaken to assess the efficacy of prilocaine $2 \%$ plain versus a mixture of lignocaine $1 \%$ and bupivacaine $0.5 \%$, each with hyaluronidase.

Methods. Seventy-five patients were recruited. Local anaesthetic was given by a two-injection transconjunctival peribulbar technique. Injection and perioperative pain were graded by visual analogue pain score (range 0-10). Akinesia and orbicularis function were graded by the surgeon.

Results. The two anaesthetic mixtures were comparable in efficacy in producing anaesthesia and akinesia. Using the Mann-Whitney $U$-test for significance, pain of injection ranked as a mean of 0.88 for prilocaine and 1.03 for lignocaine and bupivacaine $(p=0.48$, $U=635.5)$ Perioperative pain was ranked as a mean of 1.17 for prilocaine and 0.91 for lignocaine and bupivacaine $(p=0.41, U=629.0)$.

Conclusions. Prilocaine is a useful alternative anaesthetic agent for eye surgery that has low toxicity and is effective without adrenaline.
\end{abstract}

Prilocaine (Citanest) is the least toxic of commonly used local anaesthetics, but little used in ophthalmology until recently. ${ }^{1-3}$ It is structurally similar to lignocaine (lidocaine, xylocaine), but with a number of advantages: longer duration of anaesthesia, no requirement for adrenaline, greater tissue diffusion but slower systemic absorption, and 50\% less toxicity with less local irritation. ${ }^{4}$

Prilocaine has one potentially serious side effect: methaemoglobinaemia. This occurs very rarely, is dose dependent and reaches clinical significance only

From: Department of Ophthalmology, York District Hospital, Wigginton Road, York YO3 7HE, UK.

Correspondence to: Mr T. Henderson, Department of Ophthalmology, Clarendon Wing, The General Infirmary at Leeds, Belmont Grove, Leeds LS2 9NS, UK. at volumes far higher than those used for ocular anaesthesia. ${ }^{5,6}$ It is usually suspected on clinical grounds as one cause for a falling oxygen saturation detectable by pulse oximetry and is treated with methylene blue at a dose of $1 \mathrm{mg} / \mathrm{kg}$.

Peribulbar anaesthesia has the advantage over retrobulbar anaesthesia of avoiding the risk of injecting into the subarachnoid space or causing damage to the optic nerve. ${ }^{7,8}$

The study aim was to compare prilocaine with a standard mixture of lignocaine and bupivacaine. Use of adrenaline serves to limit tissue diffusion and systemic uptake and reduce the risks of cardiotoxicity and respiratory depression associated with these agents.

\section{MATERIALS AND METHODS}

The local ethics committee approved the study. Seventy-five consecutive patients due to undergo eye surgery under local anaesthesia were recruited after giving informed consent. Patients were randomised using random number tables to receive either $6 \mathrm{ml}$ prilocaine $2 \%$ plain, or $3 \mathrm{ml}$ lignocaine $1 \%$ with $3 \mathrm{ml}$ bupivacaine $0.5 \%$ and adrenaline 1 in 200000 . These were supplied in identical syringes with a study number for which the corresponding group was known only to the pharmacist. Prior to injection the trial solutions were mixed with hyaluronidase (1500 IU).

The anaesthetic mixture was administered using a modified two-injection peribulbar technique with an orange $25 \mathrm{~mm} 25$ gauge needle. This uses a medial compartment injection as well as an infero-temporal injection. ${ }^{9}$ The injection was given transconjunctivally after instillation of $1 \%$ amethocaine eye drops and was injected slowly to limit discomfort.

Following injection a McIntyre mercury bag was placed over the closed eye and secured in place. Routine operative procedure was to administer local anaesthesia prior to starting surgery on the preceding 
Table I. Mean pain scores by group

\begin{tabular}{lccc}
\hline & Prilocaine group & Lignoicaine/bupivacaine group & \\
\hline Mean pain scores for receiving LA injection & 0.88 & 1.03 & $U=635.5, p=0.479$ \\
Mean per-operative pain scores & $(0-5)$ & $(0-7)$ & $U=629.0, p=0.436$ \\
& 1.17 & 0.91 & $U=648.0, p=0.537$ \\
Mean akinesia scores & $(0-6)$ & $0.7)$ & $U=620.0, p=0.337$ \\
Mean orbicularis scores & 0.37 & $(0-2)$ & \\
Top-up required & $0-2)$ & $(0-1)$ & 1 \\
LA preferred for further surgery & $(0-2)$ & 34 & 0 \\
GA preferred for further surgery & 3 & 0 & \\
\hline
\end{tabular}

$U=$ Mann-Whitney $U$ statistic for significance in non-parametric data. Values in parentheses are the range.

LA, local anaesthetic; GA, general anaesthetic.

case. At the beginning of the operation the degree of akinesia and residual orbicularis movement was graded. Surgery was then carried out. Any complications or signs of patient discomfort were noted.

Discomfort experienced during the injection or surgery was assessed in all patients using a visual analogue pain score chart graded $0-10$ and representing no discomfort at all (0) to unbearable pain $(10) .^{10}$ There was a description for each level of discomfort so that patients unable to see the chart could still indicate a score. Patient satisfaction with local anaesthesia was assessed by asking if they would prefer local or general anaesthesia were they to undergo future eye surgery. Data were analysed using the Mann-Whitney $U$-test for significance for non-parametric data using the statistical programme SPSS.

\section{RESULTS}

\section{Pain Scores}

There was no significant difference in pain scores in the two groups. For receiving the anaesthetic the mean pain scores were prilocaine 0.88 and lignocaine/bupivacaine $1.03(p=0.479)$. Peroperative pain scores were prilocaine 1.17 and lignocaine/bupivacaine $0.91(p=0.436)$. Fourteen patients were aware of some discomfort, identified at the time by the surgeon; 8 of these patients were in the prilocaine group and 6 in the lignocaine/bupivacaine group.

\section{Movement Scores}

No significant difference was found between groups for akinesia or residual function scores. For akinesia the mean score in the prilocaine group was 0.37 and that in the lignocaine/bupivacaine group was 0.44 $(p=0.537)$. Residual lid function scores were 0.76 for prilocaine patients and 0.62 in the lignocaine/ bupivacaine group $(p=0.337)$.

\section{Duration of Procedure}

In both groups the average time from injection to commencement of surgery was 46 minutes, and then to completion of surgery was a further 35 minutes (total 81 minutes). In the prilocaine group Spearman correlation coefficients showed a modest correlation between pain scores during surgery and both the time from injection to starting surgery $(p=0.009)$ and the time from injection to the end of surgery $(p=0.01)$. A similar correlation was found for pain scores for receiving anaesthesia and peroperative discomfort $(p=0.01)$. No such correlations were shown in the lignocaine/bupivacaine group.

\section{Complications}

There was no significant difference in side effects between the two groups with the technique used. Vitreous loss occurred in only 1 patient; 1 other developed a posterior capsular tear without vitreous loss. Both patients were in the prilocaine group.

\section{Patient Satisfaction}

In the prilocaine group 38 patients indicated that they would prefer local anaesthesia for further eye surgery while 3 said they would prefer general anaesthesia. In the lignocaine/bupivacaine group all

Table II. Spearman correlation coefficients $(\rho)$

\begin{tabular}{lcc}
\hline & Prilocaine group & Lignocaine/bupivacaine group \\
\hline Pain OP v. time of injection to surgery start & 0.365 & -0.150 \\
& $\left(p=0.009^{*}\right)$ & $(p=0.12)$ \\
Pain OP v. time of injection to surgery end & 0.364 & -0.122 \\
Pain OP v. pain LA & $\left(p=0.010^{*}\right)$ & $(p=0.25)$ \\
& $\left(p=0.010^{*}\right)$ & 0.078 \\
& $(p=0.13)$ \\
\hline
\end{tabular}

OP, peroperatively; LA, local anaesthetic.

$<0.3$, no or poor correlation; $0.3-0.7$, modest correlation; $0.7-1.0$, good or high correlation.

*Significant $p$ values. 


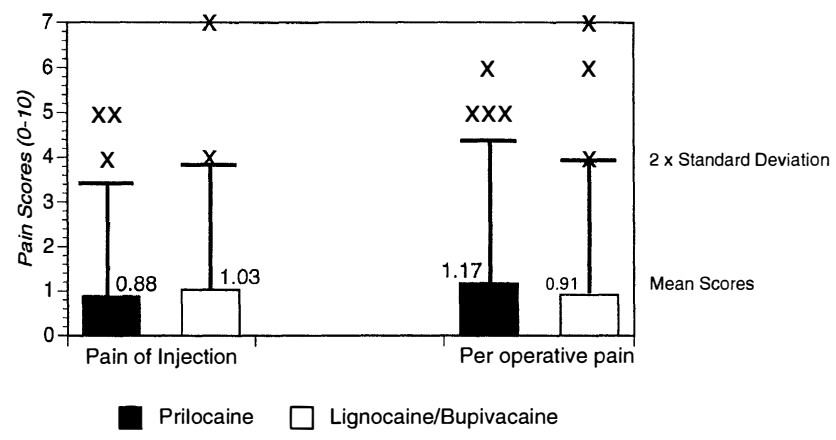

Fig. 1. Pain scores for the anaesthetic injection and peroperatively for the prilocaine group $(n=41)$ and the lignocaine/bupivacaine group $(n=38)$.

34 patients indicated they would choose local anaesthesia for any further eye surgery.

\section{Re-injection Rate}

Incomplete akinesia requiring re-injection was seen in 3 patients in the prilocaine group and 1 in the lignocaine/bupivacaine group. All 4 patients underwent subsequent surgery with minimal discomfort or movement.

\section{DISCUSSION}

The mixture of lignocaine and bupivacaine with adrenaline was used as a standard against which to compare prilocaine. Although the behaviour of anaesthetic combinations is not simply the sum of the constituents, the rationale of combining lignocaine's rapid onset with bupivacaine's prolonged effect still holds. The onset is more rapid since its $\mathrm{pH}$ is more alkaline. ${ }^{11}$ Experimentally there is no synergistic toxicity although lignocaine and bupivacaine compete for the same blocking sites. ${ }^{12,13}$ The lower mean pain score for anaesthetic administration in the prilocaine group, though not significant, may reflect a tendency towards less discomfort for the anaesthetic injection itself. A few patients did record high pain scores for anaesthetic administration in both groups, a reminder that it is not always as painless a procedure as may be suggested to the patient pre-operatively. Injections were given slowly to limit discomfort. No formal assessment of the rate of onset of block was made; experience suggests there is no clinically relevant delay in onset. Correlation calculations show modest correlation between time and pain scores only in the prilocaine group. This suggests that there may be some wearing off of the effect because of the length of time from administration. Complete recovery of motor and sensory function after prilocaine injection has been shown to occur after 258 minutes; wearing off of effect seems to start much sooner. ${ }^{14}$ Consequently, when using prilocaine we suggest that it should be given immediately prior to surgery. In this study the re-injection rate of $5.3 \%$ compares favourably with other published rates $(8-19 \%){ }^{15,16}$ Post-operative pain was not appreciably worse in either group and there were no episodes of post-operative exposure keratitis.

This study supports the wider use of prilocaine as an alternative local anaesthetic agent for eye surgery. It has been administered by retrobulbar, peribulbar, topical (as one constituent of EMLA cream) and sub-Tenon routes. ${ }^{17,18}$ It has a high safety profile, rapid onset, intermediate duration of action and is effective without adrenaline.

The authors would like to thank: C. Jakeman and P. Almack, York District Hospital Pharmacy; C. Lum for statistical advice; and the Departments of Medical Illustration, York District Hospital and St James's University Hospital, Leeds.

Key words: Peribulbar anaesthesia, Cataract surgery, Prilocaine, Lignocaine, Bupivacaine, Pain scores, Akinesia.

\section{REFERENCES}

1. Liu C, Redmond R. Choice in local anaesthesia [editorial]. Br J Ophthalmol 1993;77:758-9.

2. Saunders DC, Sturgess DA, Pemberton CJ, Morgan LH, Bourne A. Peribulbar and retrobulbar anaesthesia with Prilocaine: a comparison of two methods of local anaesthesia. Ophthalmic Surg 1993;24:842-5.

3. Simcock PR, Raymond GL, Lavin MJ, Whitley CL. Combined peribulbar injection and blunt cannula infiltration for vitreoretinal surgery. Ophthalmic Surg 1994;25:232-5.

4. Moorman LT, Kenny GS. Prilocaine as a local anaesthetic useful in ophthalmic surgery. Am J Ophthalmol 1971;72:468-71.

5. Goggin M, Crowley K, O’Malley K, Barry P, Kelly G, Blake J. Serum concentrations of prilocaine following retrobulbar block. Br J Anaesth 1990;64:107-9.

6. Bellamy MC, Hopkins PM, Halsall PJ, Ellis FR. A study into the incidence of methaemoglobinaemia after 'three-in-one' block with prilocaine. Anaesthesia 1992;47:1084-5.

7. Wittapenn JR, Rapoza P, Sternberg P Jr, Kuwaashima L, Saklad J, Patz A. Respiratory arrest following retrobulbar anaesthesia. Ophthalmology 1986;93: 867-70.

8. Kobet AA. Cerebral spinal fluid recovery of lidocaine and bupivacaine following respiratory arrest subsequent to retrobulbar block. Ophthalmic Surg 1987; 18:11-3.

9. Hustead RF, Hamilton RC, Loken RG. Periocular local anaesthesia; medial orbital as an alternative to superior nasal injection. J Cataract Refract Surg 1994;20:197-201.

10. Stevens JD, Franks WA, Orr G, Leaver PK, Cooling RJ. Four quadrant local anaesthesia technique for vitreoretinal surgery. Eye 1992;6:583-6.

11. Turner D, Williams S, Heavner J. Pleural permeability of local anaesthetics: the influence of concentration, $\mathrm{pH}$ and local anaesthetic combinations. Reg Anesth 1989;14:128-32.

12. Spiegel DA, Dexter F, Warner DS, Baker MT, Todd MM. Central nervous system toxicity of local anaesthetic mixtures in the rat. Anaesth Analg 1992;75: 922-8.

13. Brau ME, Nan C, Hemplemann G, Vogel W. Local anaesthetics potently block a potential insensitive 
potassium channel in myelinated nerve. J Gen Physiol 1995; 105:485-505.

14. Schimek F, Steuhl KP, Fahle M. Retrobulbar blocks of somatic, motor and visual nerves by local anaesthetics. Ophthalmic Surg 1993;24:171-80.

15. Ali-Melkkilä T, Virkkilä M, Leino $K$, Pälve $H$. Regional anaesthesia for cataract surgery: comparison of three techniques. Br J Ophthalmol 1993;77:771-3.

16. Whitsett JC, Balyeat HD, McClure B. Comparison of one-injection-site peribulbar anaesthesia and retro- bulbar anaesthesia. J Cataract Refract Surg 1990; 16:243-5.

17. Coelho ET, Gomes EB, Martins HS, de Sousa B. Prilocaine: an old anaesthetic agent and a new ophthalmic procedure. Ophthalmic Surg 1993;24: 612-6.

18. Sunderraj P, Kirby J, Joyce PW, Watson A. A doublemasked evaluation of lignocaine-prilocaine cream (EMLA) used to alleviate the pain of retrobulbar injection. Br J Ophthalmol 1991;75:130-2. 